Research Paper

\title{
Prognostic Impact of Preoperative Renal Insufficiency on Metastasis-Free Survival after Radical Cystectomy
}

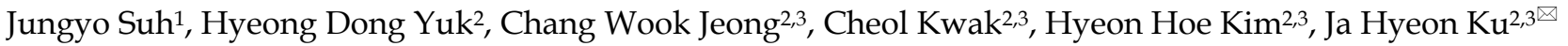 \\ 1. Department of Urology, Asian Medical Centre, Seoul, South Korea. \\ 2. Department of Urology, Seoul National University Hospital, Seoul, South Korea. \\ 3. Department of Urology, Seoul National University College of Medicine, Seoul, South Korea \\ $\square$ Corresponding author: Ja Hyeon Ku, Department of Urology, Seoul National University Hospital, Seoul National University College of Medicine, 101 \\ Daehak-ro, Jongno-gu, Seoul 03080, Korea. Tel.: + 82-2-2072-2428; Fax: + 82-2-742-4665; E-mail: kuuro70@snu.ac.kr. \\ (c) The author(s). This is an open access article distributed under the terms of the Creative Commons Attribution License (https://creativecommons.org/licenses/by/4.0/). \\ See http://ivyspring.com/terms for full terms and conditions.
}

Received: 2021.04.20; Accepted: 2021.10.17; Published: 2021.10.28

\begin{abstract}
Several studies founded that preoperative renal insufficiency is associated with a higher risk of upper tract urothelial carcinoma recurrence and mortality than normal renal function patients. However, previous studies were all retrospective; no study focused on urothelial carcinoma in the bladder and metastasis-free survival (MFS). Herein, we examined the prognostic impact of preoperative renal insufficiency on the oncologic outcomes of patients with urothelial carcinoma in the bladder after radical cystectomy. We used data from 262 patients prospectively collected from a radical cystectomy cohort between March 2016 and February 2021. The patients were divided into those with a preoperative glomerular filtration rate (GFR) of $<60 \mathrm{~mL} / \mathrm{min} / 1.73$ $\mathrm{m}^{2}$ (renal insufficiency; $n=66$ ) and those with a GFR $\geq 60 \mathrm{~mL} / \mathrm{min} / 1.73 \mathrm{~m}^{2}$ (control; $n=196$ ). We investigated MFS, cancer-specific survival (CSS), and overall survival (OS). Kaplan-Meier curves and Cox proportional hazard regression were used to estimate the prognostic impact of renal insufficiency. The mean MFS was significantly shorter in the renal insufficiency group than in the control group $(36.58 \pm 3.09$ months vs. 47.37 \pm 1.87 months); however, OS and CSS were not significantly different. T stage $\geq 3$ (hazard ratio [HR]: 2.79), lymph node positivity (HR: 2.261), and renal insufficiency (HR: 2.04) were significant independent predictors of MFS. Preoperative renal insufficiency was an independent prognostic factor for worse MFS. Well-designed randomized clinical trials and translational studies are needed to clarify the mechanism of relationship between preoperative renal insufficiency and MFS.
\end{abstract}

Key words: bladder cancer; metastasis; radical cystectomy; renal insufficiency; survival; urothelial carcinoma

\section{Introduction}

Urothelial carcinoma of the bladder (UCB) is the $10^{\text {th }}$ most common cancer worldwide and the $13^{\text {th }}$ leading cause of cancer-related deaths [1]. Radical cystectomy $(\mathrm{RC})$ is recommended for muscle-invasive bladder cancer (MIBC) and certain aggressive phenotypes of non-MIBC (NMIBC). However, up to $70 \%$ of patients experience local or distant recurrence within two years after complete removal of the primary cancer [2]. Distant metastasis decreases life expectancy and requires systemic therapy. Therefore, identifying patients at higher risk of distant metastasis is important, especially among those who require RC. Preoperative renal insufficiency is associated with all-cause mortality in several malignancies [3]. A recent meta-analysis found that preoperative renal insufficiency is associated with a higher risk of upper tract urothelial carcinoma (UC) recurrence and mortality [4]. Two previous studies reported the effect of preoperative renal insufficiency on oncological outcomes in patients with bladder UC and upper urinary tract UC (UTUC) [5,6]. However, these previous studies were based on retrospective data from the 1990s to 2010s and may have been highly vulnerable to recall or sampling biases. Further, the clinical impact of renal insufficiency on metastasisfree survival (MFS) in cases of UCB treated with RC remains unclear.

In this study, we investigated the prognostic impact of preoperative renal insufficiency on MFS in a nonrandomized prospective cohort of patients with UCB. The secondary endpoints were overall survival 
(OS) and cancer-specific survival (CSS) in patients with preoperative renal insufficiency.

\section{Materials and Methods}

\section{Ethics Approval and Informed Consent}

This study was approved by the Seoul National University Hospital (SNUH) Institutional Review Board (IRB). Informed consent for academic use of the clinical data was obtained from each participant at the time of enrolment in the prospective registry [7]. For this ad-hoc study, the SNUH IRB approved the academic use of registry data focused on renal insufficiency and oncological outcomes after RC. All the study processes were performed in accordance with relevant guidelines and regulations.

\section{Patient selection and cohort follow-up protocols}

For this analysis, we used data from the SNUH Prospectively Enrolled Registry for Urothelial Carcinoma treated with $\mathrm{RC}$, a sub-cohort of the multidisciplinary genitourinary cancer registry of a high-volume tertiary center [7]. Patients who underwent RC between March 2016 and February 2021 at SNUH were evaluated. The inclusion criteria were as follows: patients older than 18 years and who underwent RC due to histologically confirmed MIBC or Bacille Calmette Guérin (BCG)-refractory NMIBC. Patients with non-UC on final pathological examination and those who underwent neoadjuvant chemotherapy were excluded (Figure 1). All patients underwent RC with standard pelvic lymph node dissection.

The preoperative glomerular filtration rate (GFR) was calculated using the Modification of Diet in Renal Disease equation $(G F R=186.3 \times$ serum creatinine level $(\mathrm{mg} / \mathrm{dL})^{-1.154} \times$ age $^{-0.203} \times 0.742$ (if female)) [8]. Patients were divided into two groups based on the preoperative GFR. Patients with a calculated GFR of $<60 \mathrm{~mL} / \mathrm{min} / 1.73 \mathrm{~m}^{2}$ were assigned to the renal insufficiency group, and those with a calculated GFR of $\geq 60 \mathrm{~mL} / \mathrm{min} / 1.73 \mathrm{~m}^{2}$ were assigned to the control group. All the preoperative laboratory tests were performed within one month before RC. If the results of any laboratory tests were abnormal, we repeated those laboratory tests at the time of admission. Patient selection for RC followed current guidelines and recommendations, i.e., clinical $\mathrm{T}$ stage $\geq 2$ or treatment-refractory cT1 [9]. High-risk patients, such as those with pathologic stage T3 or $\geq \mathrm{N} 1$, were treated with cisplatin-based adjuvant chemotherapy. Metastasis was assessed using computed tomography every six months for three years after RC and annually thereafter. If the patient had any unusual symptoms, we performed additional laboratory and imaging tests, including positron emission tomography.

\section{Statistical analysis}

The primary endpoint was MFS, while the secondary endpoints were OS and CSS within the follow-up period. Continuous variables were described as means (interquartile ranges), and categorical variables were described as frequencies (percentages). Continuous variables were compared using Student's t-test, and categorical variables were compared using the chi-square test or Fisher's exact test. Kaplan-Meier curves and log-rank tests were used to compare MFS, OS, and CSS of the two groups. Cox proportional hazard regression analysis was performed for MFS, OS, and CSS using known risk factors: age, pathologic $\mathrm{T}$ stage, pathologic $\mathrm{N}$ stage, sex, history of UTUC, and renal function. Patients were divided into three age groups ( $<65$ years, $65-75$ years, and $>75$ years). Statistical analyses were performed using Python 3.9.0 based on packages dependent on SciPy [10]. Statistical significance was set at $p<0.05$, and all reported $p$-values were two-sided.

\section{Results}

\section{Patient characteristics}

A total of 262 patients who underwent RC at SNUH were included in the analysis. Sixty-six patients were assigned to the renal insufficiency group and 196 patients to the control group (Figure 1). The average GFR of the renal insufficiency group was $40.21 \pm 15.43 \mathrm{~mL} / \mathrm{min} / 1.73 \mathrm{~m}^{2}$, and that of the control group was $88.50 \pm 19.42 \mathrm{~mL} / \mathrm{min} / 1.73 \mathrm{~m}^{2}$. The renal insufficiency group was significantly older than the control group $(73.64 \pm 10.53$ years vs. $69.91 \pm 10.05$ years, $p=0.01$ ). Sex, body mass index, pathologic T stage, and pathologic $\mathrm{N}$ stage were not significantly different between the two groups. Diabetes mellitus and hypertension were found more frequently in the renal insufficiency group, along with a history of UTUC. Laboratory tests showed that renal insufficiency was correlated with low hemoglobin levels, high potassium levels, and high uric acid levels (Table 1).

\section{Kaplan-Meier survival analysis}

During the $18.7 \pm 14.4$ months of follow-up, 43 patients $(16.4 \%)$ had metastasis and 31 patients $(11.8 \%)$ died. Metastasis occurred in 16 patients $(24.2 \%)$ in the renal insufficiency group and 27 patients (13.7\%) in the control group. The mean MFS was significantly shorter in the renal insufficiency group than in the control group $(36.58 \pm 3.09$ months vs. $47.37 \pm 1.87$ months, $p=0.01$ ) (Figure $2 \mathrm{~A}$ ). Nine 
$(13.6 \%)$ patients died in the renal insufficiency group and $22(11.2 \%)$ died in the control group. The OS and CSS of the renal insufficiency and control groups were not significantly different (Figure 2B, C).

Table 1. Demographics of the renal insufficiency and control groups

\begin{tabular}{|c|c|c|c|}
\hline & Renal insufficiency & Control & $p$-value \\
\hline Number of patients & $N=66$ & $N=196$ & \\
\hline Age, yr. & $73.64(67.8-81.0)$ & $69.91(62.3-77.0)$ & 0.011 \\
\hline Body mass index, $\mathrm{kg} / \mathrm{m}^{2}$ & $23.31(21.0-25.4)$ & $23.65(21.0-25.7)$ & 0.482 \\
\hline Diabetes Miletus, $n(\%)$ & $22(33.3)$ & $38(19.4)$ & 0.020 \\
\hline Hypertension, $n(\%)$ & $43(65.2)$ & $91(46.4)$ & 0.008 \\
\hline $\begin{array}{l}\text { History of upper tract } \\
\text { urothelial carcinoma, } n(\%)\end{array}$ & $15(22.7)$ & $2(1.0)$ & $<0.001$ \\
\hline Sex, $n(\%)$ & & & 0.281 \\
\hline Male & $55(83.3)$ & $151(77.9)$ & \\
\hline Female & $11(16.7)$ & $45(23.0)$ & \\
\hline Pathologic T stage, $n(\%)$ & & & 0.339 \\
\hline pT0 & $15(22.7)$ & $30(15.3)$ & \\
\hline pT1 & $21(31.8)$ & $73(37.2)$ & \\
\hline pT2 & $9(13.6)$ & 39 (19.9) & \\
\hline pT3-4 & $21(31.8)$ & $54(27.6)$ & \\
\hline Pathologic N stage, $n(\%)$ & & & 0.925 \\
\hline $\mathrm{pNx}$ and $\mathrm{pN} 0$ & $56(84.8)$ & $170(86.7)$ & \\
\hline $\mathrm{pN} 1$ & $4(6.1)$ & $10(5.1)$ & \\
\hline pN2 & $6(9.1)$ & $16(8.1)$ & \\
\hline Histologic variants, $n(\%)$ & $10(19.6)$ & 30 (18.1) & 0.805 \\
\hline $\begin{array}{l}\text { Lymphovascular invasion, } n \\
(\%)\end{array}$ & $17(25.8)$ & $36(18.5)$ & 0.203 \\
\hline $\begin{array}{l}\text { Concomitant carcinoma in situ, } \\
n(\%)\end{array}$ & $20(30.3)$ & $82(41.8)$ & 0.096 \\
\hline ADJ chemotherapy, $n(\%)$ & $9(13.6)$ & 30 (15.3) & 0.742 \\
\hline Hemoglobin, g/dL & $12.04(10.8-13.1)$ & $13.10(11.9-14.3)$ & $<0.001$ \\
\hline Potassium, mmol/L & $4.56(4.3-4.8)$ & $4.20(4.0-4.4)$ & $<0.001$ \\
\hline Uric acid, mg/dL & $6.11(5.4-7.1)$ & $5.17(4.3-6.1)$ & $<0.001$ \\
\hline
\end{tabular}

\section{Univariate and Multivariable Cox proportional hazard regression}

The univariate Cox proportional hazard regression analysis indicated that pathologic $\mathrm{T}$ stage $(\geq \mathrm{T} 3)$ (hazard ratio [HR]: 4.18, 95\% confidence interval $[C I]: 2.28-7.65, p<0.01$ ), lymph node metastasis (HR: 4.39, 95\% CI: 2.24-8.60, $p<0.01)$ and history of UTUC (HR: 2.44, 95\% CI: 1.08-5.50, $p=0.03$ ) were significantly associated with MFS. Renal function was also significantly associated with worse MFS (HR: 2.13, 95\% CI: 1.15-3.96, $p=0.02)$. In the multivariable analysis, pathologic $\mathrm{T}$ stage (HR: 2.79, 95\% CI: 1.35-5.75, $p<0.01$ ), lymph node metastasis (HR: 2.26, 95\% CI: 1.03-4.96, $p=0.04$ ), and renal insufficiency (HR: 2.04, 95\% CI: 1.07-3.87, $p=0.03$ ) remained as independent prognostic factors for MFS (Table 2).

Table 2. Univariate and multivariate Cox proportional hazard regression for metastasis-free survival

\begin{tabular}{|c|c|c|c|c|c|c|}
\hline \multirow[t]{2}{*}{ Variable } & \multicolumn{3}{|c|}{ Univariate } & \multicolumn{3}{|c|}{ Multivariable } \\
\hline & $\begin{array}{l}\text { Hazard } \\
\text { ratio }\end{array}$ & $\begin{array}{l}\text { Confidence } \\
\text { interval }\end{array}$ & $p$-value & $\begin{array}{l}\text { Hazard } \\
\text { ratio }\end{array}$ & $\begin{array}{l}\text { Confidence } \\
\text { interval }\end{array}$ & $p$-value \\
\hline Age & & & 0.407 & & & \\
\hline$<65$ years & Ref & & & & & \\
\hline $65-75$ years & 0.823 & $0.363-1.867$ & & & & \\
\hline$>75$ years & 1.329 & $0.636-2.777$ & & & & \\
\hline $\begin{array}{l}\text { Pathologic } \mathrm{T} \\
\text { stage }(\geq \mathrm{T} 3)\end{array}$ & 4.175 & $2.277-7.654$ & $<0.001$ & 2.786 & $1.349-5.754$ & 0.006 \\
\hline $\begin{array}{l}\text { Lymph node } \\
\text { metastasis }\end{array}$ & 4.390 & $2.240-8.603$ & $<0.001$ & 2.261 & $1.031-4.957$ & 0.042 \\
\hline Sex (Female) & 1.040 & $0.524-2.064$ & 0.912 & & & \\
\hline $\begin{array}{l}\text { Renal } \\
\text { insufficiency }\end{array}$ & 2.129 & $1.146-3.956$ & 0.017 & 2.037 & $1.074-3.866$ & 0.029 \\
\hline $\begin{array}{l}\text { History of } \\
\text { UTUC }\end{array}$ & 2.441 & $1.084-5.500$ & 0.031 & & & \\
\hline
\end{tabular}

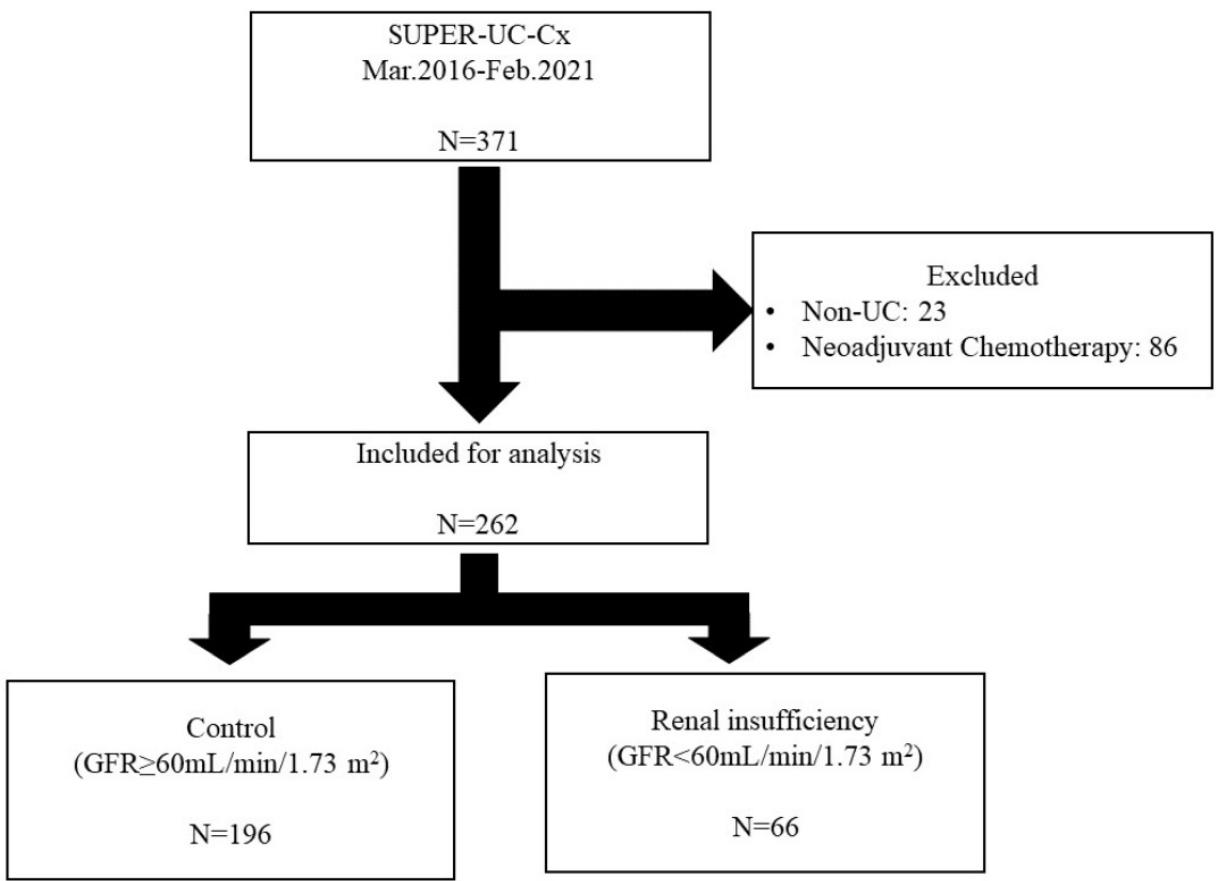

Figure 1. Flow chart of inclusion and exclusion criteria and patient grouping based on pre-operative estimated glomerular filtration rate. SUPER-UC-Cx: Seoul National University Hospital Prospectively Enrolled Registry for Urothelial Carcinoma treated by Radical Cystectomy; UC: urothelial carcinoma; GFR: glomerular filtration rate. 

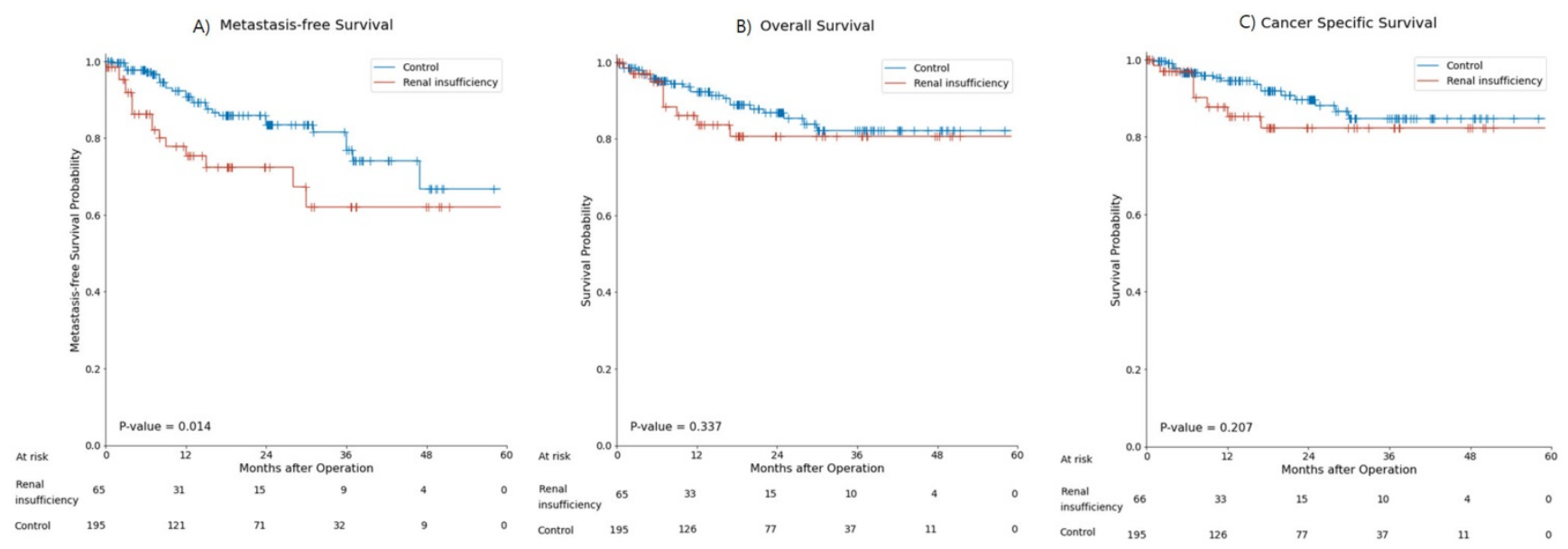

Figure 2. Kaplan-Meier curve for (A) metastasis-free survival, (B) overall survival, (C) and cancer-specific survival in the renal insufficiency and control groups.

Table 3. Univariate and multivariate Cox proportional hazard regression for overall survival

\begin{tabular}{|c|c|c|c|c|c|c|}
\hline & \multicolumn{3}{|c|}{ Univariate } & \multicolumn{3}{|c|}{ Multivariable } \\
\hline & $\begin{array}{l}\text { Hazard } \\
\text { ratio }\end{array}$ & $\begin{array}{l}\text { Confidence } \\
\text { interval }\end{array}$ & $p$-value & $\begin{array}{l}\text { Hazard } \\
\text { ratio }\end{array}$ & $\begin{array}{l}\text { Confidence } \\
\text { interval }\end{array}$ & $p$-value \\
\hline Age & & & 0.108 & & & 0.166 \\
\hline$<65$ years & Ref & & & & & \\
\hline $65-5$ years & 1.451 & $0.486-4.332$ & & & & \\
\hline$>75$ years & 2.565 & $0.945-6.965$ & & & & \\
\hline $\begin{array}{l}\text { Pathologic } T \\
\text { stage }(\geq \mathrm{T} 3)\end{array}$ & 4.001 & $1.957-8.178$ & $<0.001$ & 2.603 & $1.118-6.061$ & 0.027 \\
\hline $\begin{array}{l}\text { Lymph node } \\
\text { metastasis }\end{array}$ & 4.366 & $2.069-9.213$ & $<0.001$ & 2.512 & $1.052-5.998$ & 0.038 \\
\hline Sex (Female) & 0.584 & $0.224-1.522$ & 0.271 & & & \\
\hline $\begin{array}{l}\text { Renal } \\
\text { insufficiency }\end{array}$ & 1.460 & $0.671-3.175$ & 0.340 & & & 0.326 \\
\hline $\begin{array}{l}\text { History of } \\
\text { UTUC }\end{array}$ & 0.826 & $0.197-3.464$ & 0.794 & & & \\
\hline
\end{tabular}

Table 4. Univariate and multivariate Cox proportional hazard regression for cancer-specific survival

\begin{tabular}{|c|c|c|c|c|c|c|}
\hline Variables & $\begin{array}{l}\text { Hazard } \\
\text { ratio }\end{array}$ & $\begin{array}{l}\text { Confidence } \\
\text { interval }\end{array}$ & $p$-value & $\begin{array}{l}\text { Hazard } \\
\text { ratio }\end{array}$ & $\begin{array}{l}\text { Confidence } \\
\text { interval }\end{array}$ & $p$-value \\
\hline Age & & & 0.155 & & & 0.221 \\
\hline$<65$ years & Ref & & & & & \\
\hline $65-75$ years & 0.974 & $0.297-3.193$ & & & & \\
\hline$>75$ years & 2.148 & $0.772-5.976$ & & & & \\
\hline $\begin{array}{l}\text { Pathologic } \mathrm{T} \\
\text { stage }(\geq \mathrm{T} 3)\end{array}$ & 5.216 & $2.301-11.825$ & 0.001 & 4.941 & $2.157-11.317$ & $<0.001$ \\
\hline $\begin{array}{l}\text { Lymph node } \\
\text { metastasis }\end{array}$ & 3.866 & $1.646-9.077$ & 0.002 & & & 0.221 \\
\hline Sex (Female) & 0.567 & $0.194-1.653$ & 0.299 & & & \\
\hline $\begin{array}{l}\text { Renal } \\
\text { insufficiency }\end{array}$ & 1.708 & $0.736-3.963$ & 0.213 & & & 0.181 \\
\hline $\begin{array}{l}\text { History of } \\
\text { UTUC }\end{array}$ & 1.035 & $0.244-4.392$ & 0.963 & & & \\
\hline
\end{tabular}

Univariate and Multivariable analyses for OS showed that pathologic $\mathrm{T}$ stage (HR: 2.60, 95\% CI: $1.12-6.06, p=0.03$ ) and lymph node metastasis (HR: 2.51, 95\% CI: $1.05-6.00, p=0.04)$ were significant independent prognostic factors (Table 3). Univariate and Multivariable analyses for CSS showed that pathologic T stage (HR: 4.94, 95\% CI: 2.16-11.32, $p<$ 0.01 ) was the only significant independent prognostic factor (Table 4).

\section{Discussion}

This study investigated the prognostic impact of preoperative renal insufficiency on MFS, OS, and CSS in patients with UCB who underwent RC. In this study, renal insufficiency was not a prognostic factor for OS or CSS. However, renal insufficiency, along with pathologic $\mathrm{T}$ stage and lymph node metastasis, were independent prognostic factors for MFS.

Recurrence after RC is relatively common in patients with advanced bladder cancer [11]. Although most studies do not distinguish between local recurrence and metastasis, some studies have shown that up to $50 \%$ of patients experience distant metastasis after RC [11]. A recent study conducted by Park et al. [12] reported that $59.9 \%$ of patients with pathologic TanyN1-3M0 disease experienced metastasis within 3 years after RC. The 5-year survival rate of RC varies by initial presentation, from $77 \%$ for superficial cancer to $46 \%$ for MIBC [13]. However, the 5 -year survival is notably decreased to less than $15 \%$ in patients with metastatic UC [14]. Therefore, careful patient stratification and intensive follow-up protocols for high-risk patients are particularly important. In this study, we found that renal insufficiency increases the risk of metastasis. We also identified pathologic $\mathrm{T}$ stage and $\mathrm{N}$ stage to be significantly associated with metastasis. We suggest that patients with these risk factors should be followed up more carefully for early identification of metastasis.

Renal insufficiency is associated with poor outcomes in UC patients in various ways. A well-established hypothesis suggests that chronic kidney disease (CKD) is a predictor of poor survival in cancer patients because decreased renal function makes the selection or therapeutic dosing of chemotherapeutic agents difficult [15]. Most 
chemotherapeutic agents are nephrotoxic; therefore, patients with advanced CKD experience a vicious cycle of decreasing renal function and decreasing therapeutic effects. Conversely, renal insufficiency can lead to the development of UC and promote the progression of other malignancies. Lin et al. [16] found a higher incidence of oral, colorectal, liver, blood, breast, renal, upper urinary tract, and bladder cancer in patients with end-stage renal disease who were undergoing dialysis than in healthy individuals. Leppert et al. [17] reported that CKD itself increased the risk of $\mathrm{UC}$, although the risk of other malignancies was not significantly increased. A recent meta-analysis showed that postoperative CKD had a poor prognostic impact on UC recurrence and patient survival [4]. This study focused on the prognostic impact of preoperative renal insufficiency on MFS after RC in patients with UCB. Renal insufficiency was an independent prognostic factor for MFS (HR: 2.04, 95\% CI: 1.07-3.87, $p=0.03)$, although its prognostic impact on OS and CSS was not significant. Owing to a relatively short follow-up period and a limited number of patients, the proportion of deceased patients was only about 10\% (31/265 patients) of all patients in this study, which is not enough to determine the prognostic impact of renal insufficiency on OS and CSS in this study. Further studies with a longer follow-up period are warranted; large population-based studies should also be conducted that apply the findings of this study.

The mechanism by which renal insufficiency affects MFS has not been clearly demonstrated and we did not examine it in this study. However, we suggest a potential mechanism of action, where renal insufficiency induces hypoxia and increases toxic agent-mediated cancer cell growth at metastatic sites. Recently, Soave et al. [18] showed that more than $25 \%$ of patients with RC have an increased risk of circulating tumor cells (CTCs), which are a potential source of metastasis [19]. CTCs in venous blood increase the likelihood of cancer cell migration to solid organs and the progression of metastasis under the proper conditions. In this study, patients with renal insufficiency tended to have lower hemoglobin levels, higher potassium levels, and higher uric acid levels than patients in the control group. Anemia is a well-known complication of CKD [20], and the hypoxia-inducible factor-mediated pathway plays an important role in metastasis [21]. Additionally, high uric acid is relatively common in patients with renal impairment [22], and this is a poor prognostic factor for CKD development [22] and cancer progression [23]. However, a better-designed study on CKD and metastasis is required to answer these questions.

This study has several limitations. Although we investigated the endpoints in a prospective cohort, we did not perform randomization; therefore, caution should be exercised before applying the results of this study in clinical settings. This study only contained data from a single institution; thus, external validation of the findings is needed. Another important limitation is that data for pre-operative hydronephrosis were not available in this study. Pre-operative hydronephrosis can impact both renal function and prognosis in cases of UCB [24]. Moreover, we did not provide a potential mechanism of action by which preoperative renal insufficiency promotes metastasis. Despite these limitations, this is the first study to reveal the effect of preoperative renal insufficiency on MFS after definitive treatment of bladder cancer in a prospective cohort. Well-designed randomized clinical trials and translational studies are needed to clarify the mechanism of action driving this phenomenon.

In conclusion, preoperative renal insufficiency was an independent prognostic factor for shorter MFS. Renal insufficiency was not significantly associated with OS or CSS. Therefore, we suggest careful follow-up in patients with UCB with renal insufficiency before RC. The mechanism underlying the effect of renal insufficiency on MFS is unclear; however, we suggest hypoxia-induced activation of micrometastatic cancer cells. Further investigation is required to clarify this phenomenon.

\section{Abbreviations}

CSS: cancer-specific survival; GFR: glomerular filtration rate; MFS: metastasis-free survival; MIBC: muscle-invasive bladder cancer; OS: overall survival; RC: Radical cystectomy; UCB: Urothelial carcinoma of the bladder; UTUC: upper urinary tract UC.

\section{Acknowledgements}

\section{Author Contributions}

Conceptualization, J.S. and J.H.K.; methodology and formal analysis, J.S.; Python, v.3.9.0.; resources and data curation: H.D.Y., C.W.J.; writing-original draft preparation, J.S.; writing - review and editing, C.K. and H.H.K.; visualization, J.S.; supervision, CW. Jeong, C.K., H.H.K. and J.H.K. All authors have read and agreed to the published version of the manuscript.

\section{Data Availability Statement}

The data that support the findings of this study are available on request from the corresponding author, JHK. However, the data are not publicly available due to privacy and ethical issue of research participants. 


\section{Competing Interests}

The authors have declared that no competing interest exists.

\section{References}

1. Bray F, Ferlay J, Soerjomataram I, et al. Global cancer statistics 2018: GLOBOCAN estimates of incidence and mortality worldwide for 36 cancers in 185 countries. CA Cancer J Clin. 2018; 68: 394-424.

2. Koh DM, Husband JE. Patterns of recurrence of bladder carcinoma following radical cystectomy. Cancer Imaging. 2003; 3: 96-100.

3. Yang Y, Li HY, Zhou Q, et al. Renal Function and all-cause mortality risk among cancer patients. Medicine. 2016; 95: 1-8.

4. Cao J, Zhao X, Zhong Z, et al. Prognostic value of pre-operative renal insufficiency in urothelial carcinoma: A systematic review and meta-analysis. Sci Rep. 2016; 6: 1-9.

5. Momota M, Hatakeyama S, Tokui N, et al. The impact of preoperative severe renal insufficiency on poor postsurgical oncological prognosis in patients with urothelial carcinoma. Eur Urol Focus. 2019; 5: 1066-1073.

6. Matsumoto A, Nakagawa T, Kanatani A, et al. Preoperative chronic kidney disease is predictive of oncological outcome of radical cystectomy for bladder cancer. World J Urol. 2018; 36: 249-256.

7. Jeong CW, Suh J, Yuk HD, et al. Establishment of the Seoul national university prospectively enrolled registry for genitourinary cancer (SUPER-GUC): A prospective, multidisciplinary, bio-bank linked cohort and research platform. Investig Clin Urol. 2019; 60: 235-243.

8. Levey AS, Coresh J, Greene T, et al. Using standardized serum creatinine values in the modification of diet in renal disease study equation for estimating glomerular filtration rate. Ann Intern Med. 2006; 145: 247-254.

9. Alfred Witjes J, Lebret T, Compérat EM, et al. Updated 2016 EAU Guidelines on muscle-invasive and metastatic bladder cancer. Eur Urol. 2017; 71: 462-475.

10. Virtanen P, Gommers R, Oliphant TE, et al. SciPy 1.0: Fundamental algorithms for scientific computing in Python. Nat Methods. 2020; 17: 261-272.

11. Mari A, Campi R, Tellini R, et al. Patterns and predictors of recurrence after open radical cystectomy for bladder cancer: A comprehensive review of the literature. World J Urol. 2018; 36: 157-170.

12. Pak S, You D, Jeong IG, et al. Adjuvant chemotherapy versus observation after radical cystectomy in patients with node-positive bladder cancer. Sci Rep. 2019; 9: 1-7

13. May M, Helke $C$, Nitzke $T$, et al. Survival rates after radical cystectomy according to tumor stage of bladder carcinoma at first presentation. Urol Int. 2004; 72: 103-111.

14. Bajorin BDF, Dodd PM, Mazumdar M, et al. Long-term survival in metastatic transitional-cell carcinoma and prognostic factors predicting outcome of therapy. J Clin Oncol. 1999; 17: 3173-3181.

15. Malyszko J, Tesarova P, Capasso G, et al. The link between kidney disease and cancer: complications and treatment. Lancet. 2020; 396: 277-287.

16. Lin MY, Kuo MC, Hung CC, et al. Association of dialysis with the risks of cancers. PLoS One. 2015; 10: 1-13

17. Leppert JT, Lamberts RW, Thomas I-C, et al. Incident CKD after radical or partial nephrectomy. J Am Soc Nephrol. 2017: 207-216.

18. Soave A, Riethdorf S, Dahlem R, et al. Detection and oncological effect of circulating tumour cells in patients with variant urothelial carcinoma histology treated with radical cystectomy. BJU Int. 2017; 119: 854-861.

19. Micalizzi DS, Maheswaran S, Haber DA. A conduit to metastasis: Circulating tumor cell biology. Genes Dev. 2017; 31: 1827-1840.

20. Fishbane S, Spinowitz B. Update on Anemia in ESRD and Earlier Stages of CKD: Core Curriculum 2018. Am J Kidney Dis. 2018; 71: 423-435.

21. Rankin EB, Giaccia AJ. Hypoxic control of metastasis. Science. 2016; 352: 175180.

22. Giordano C, Karasik O, King-Morris K, et al. Uric Acid as a Marker of Kidney Disease: Review of the Current Literature. Dis Markers. 2015; 2015: 382928.

23. Fini MA, Elias A, Johnson RJ, et al. Contribution of uric acid to cancer risk, recurrence, and mortality. Clin Transl Med. 2012; 1: 1-15.

24. Bartsch GC, Kuefer R, Gschwend JE, et al. Hydronephrosis as a prognostic marker in bladder cancer in a cystectomy-only series. Eur Urol. 2007; 51: 690698. 